\title{
Valero-Garcés, C. \& Tipton, R. (2017). Ideology, ethics and policy development in public service interpreting and translation. Bristol \& Blue Ridge Summit: Multilingual Matters. 230 pp.
}

Public service interpreting and translation (PSIT) has been described as liaison interpreting (Gentile, Ozolins, \& Vasilakakos, 1996), community interpreting (Hale, 2007) and public service interpreting (Corsellis, 2008) over the past few decades. It enables people who do not speak or are not fluent speakers of the official language(s) of a country, to equally enjoy a range of public services, including legal assistance, health care, education, employment, housing, etc. Against the backdrop that migration is a commonplace phenomenon and various national and many local legislative bodies have mandated that these social services must, by law, be accessible to all members of the community, irrespective of their native language, PSIT will assume an increasingly important role in ensuring equality and social justice for the underprivileged ones.

In recent years, PSIT has developed rapidly and become an active field of research within the discipline of translation studies. It has received much attention from the research community, and is progressing on its way to professionalization. Up to now, researchers from different fields have explored many issues of interest. To be specific, Corsellis (2008) provides a preliminary introduction to PSI by expounding on the expertise, role and training of public service interpreters through establishing a professional framework. The challenges and opportunities for public service interpreters are analysed by Munyangeyo, Rabadán-Gómez, and Webb (2016) to explore the possibility of offering a more fitting regulation for such a growing industry, which sheds light on the roles of all stakeholders involved in the provision and delivery of PSI. However, that still leaves many issues uncovered in PSIT, such as power relations, ethics and ideology, especially in the settings of social conflict. Therefore, Valero-Garcés and Tipton's work Ideology, Ethics and Policy Development in Public Service Interpreting and Translation is an encouraging step in this direction.

The volume is a book-length treatment of PSIT in the aspects of violent conflict, population displacement, migration, gender-based violence, human rights violations and mental health trauma. It illuminates the evolving nature of ethics and ideology in a range of settings, and explores their implications for PSIT service organization, perception and delivery. Apart from the tables and figures, abbreviations, introduction and index, it comprises of ten chapters, which are further subdivided into two parts: '(Re)defining Concepts in Different Policy Contexts' and 'Experiences from the Field'.

In Chapter 1, titled 'Interpreters in history: A reflection on the question of loyalty', Cáceres Würsig focuses on the concept of loyalty and its relation to ideology by comparing the interpreting practices in diplomacy and intelligence in the following periods: Reconquista, the discovery of the New World, Spanish colonization, and the contemporary era. It highlights the fact that different governments seek to control interpreting activities and prefer to employ native interpreters in situations of military conflict since interpreters "deal with sensitive information and have the capacity to influence military and diplomatic decisions." (p. 18). The findings further strengthen the relationship between ideology and interpreting/translation, particularly in situations of violent conflict, as exemplified in interpreters/translators' loyalty in lineage, religion, nationality and long-term commitment.

The relevance of the concept 'recognition' in PSIT is explored by Martín Ruano in Chapter 2, 'Developing public service translation and interpreting under the paradigm of recognition'. She argues that the concepts of accuracy and fidelity, in the codes of ethics of the translation profession, entail simplifying and self-deprecating assumptions about the differences between the parties involved in translation/interpreting. On the one hand, these concepts exclude difference in the name of hegemonic ideologies; on the other hand, they cannot meet the conflictual demands and expectations of our diverse and 
asymmetrical societies. Therefore, 'recognition' should be conceptualized in the following two ways: as recognition of the particularities and legitimate differences of the parties involved in the translation situation, and as recognition of the intervenient participation of PSIT practitioners.

In Chapter 3, 'Interpreting-as-conflict: PSIT in third sector organizations and the impact of third way politics', Tipton aims to analyse the language support policy adopted by the New Labor government, its impact on human service delivery and the development of PSI in the third sector (i.e., the private non-profit and voluntary sector). On the basis of a survey on language support and many interviews with service providers, she concludes that the third sector organizations should adopt a mixed regime of language support combining both professional and volunteer interpreting services to achieve legitimation of the profession, though it may risk limiting their accountability to service users with a limited language proficiency. Her findings provide some valuable insights for the legitimation of voluntary interpreting services, meanwhile, they also pose some challenges for the training of service providers. Though the survey is still narrow in research scope, its result hopefully paves the way for future large-scale studies in this new field.

In Chapter 4 titled 'Political ideology and the de-professionalization of public service interpreting', Gentile attempts to explore empirically how and to what extent the policies implemented by the Netherlands and the UK contribute to the deprofessionalization of PSI in those states. The analysis is based on quantitative and qualitative data collected via questionnaires among 114 interpreters from the two countries above-mentioned. In her research, Gentile adopts Moira Inghilleri's research methodology to expound the complex interconnections between the societal and personal level of interpreting practices. The findings reveal that the implementation of nationalist ideologies, such as the privatisation and outsourcing of PSI, has hindered the professionalization of PSI in the aspects of remuneration, professional status and social value, and damaged public perception of the profession.

The study of ethics in the training of translators and interpreters constitutes the central theme of Chapter 5, 'A sea of troubles': Ethical dilemmas from war zones to the classroom'. In this chapter, Brander de la Iglesia explores the notion of moral development and ethics of war by drawing on findings from the fields of psychology, philosophy and applied ethics. Then, she applies these insights to theorize what constitutes an ethical dilemma as a starting point for the study of ethics in the interpreting classroom (p. 85). Accordingly, she argues for a situation-based workplace ethic evolving through time, which serves to develop students' moral judgment and construct their ethical consciousness. This workplace ethic is of great reference especially considering that there is an absence of ethics courses in the education and training of public service interpreters and translators.

Part II, titled 'Experiences from the field', includes five case studies on interpreters' mediation with asylum seekers, refugees and trauma survivors in settings such as courtrooms, correctional facilities and criminal investigations. It attempts to offer new insights into different types of legal events and provide us with new perspectives on the training of interpreters.

Using surveys and interviews with staff, interpreters and inmates, Valero-Garcés, in Chapter 6, 'Ethical codes and their impact on prison communication', investigates communication among inmates in the Spanish prisons where ethical conflicts may arise. Her research focuses on the differing perceptions of prison staff and interpreters in relation to inmates' rights to communicate, as well as the potential ethical dilemmas and consequences. The findings reveal that there exist great disparities between prison staff and interpreters in their understanding of whether certain ethical principles have been met in each of their professions. To be specific, the prison staff values experience and knowledge of the contact languages, while the interpreters emphasize fidelity to content and impartiality. 
In Chapter 7, titled 'Virtual presence, ethics and videoconference interpreting: Insights from court settings', Devaux examines court interpreters' perceptions of ethical issues arising from the use of videoconference interpreting in England and Wales. This study is based on Camayd-Freixas' (2013) research findings that interpreters benefit from the application of complementary theories of ethics, such as deontology, consequentialism, moral sentiments and virtue ethics, in their rationalization process of ethical issues. Devaux seeks to identify and theorize the range of ethical issues reported by the three court interpreters he interviewed. His research reveals that videoconference systems interact with interpreters' rationalization process in dealing with ethical issues, and further empirical studies are needed to examine how the four theories of ethics can improve interpreters' perception of virtue ethics. Apart from that, the interpreters seem to privilege a deontological approach in the absence of any guidelines in the National Register of Public Service Interpreters' Code of Professional Conduct.

In Chapter 8, 'Participants' and interpreters' perception of the interpreter's role in interpreter-mediated investigative interviews of minors,' Salaets and Balogh compare the perceptions of legal interpreters, police officers, lawyers, judges, psychologists, psychiatrists, behavioral scientists, child support workers, etc. in Belgium and Italy. Their research findings indicate that, due to historical differences, professionals in Belgium are not always aware of the interpreter's role, and they try to impose their opinions on how interpreters should act, while professionals and interpreters in Italy share the same opinion about the role of interpreters as active participants. Though no generalizable conclusions can be drawn due to small sample size, as the two authors admit, interpreters are expected to possess interpersonal and intercultural competences, apart from interpreting skills, in order to facilitate the process of questioning minors. The comparison indicates the urgent need of special training on the specific skills for all professionals involved in the process, and highlights the importance of close cooperation and teamwork between them.

Ethical issues are analysed by Tryuk in Chapter 9, 'Conflict, tension, aggression: Ethical issues in interpreted asylum hearings at the Office for Foreigners in Warsaw'. She seeks to explore how an interpreter overcomes conflicts, tensions, emotions and verbal aggression between officers and refugee applicants during an interpreter-mediated interaction. Through a mixed-methods approach, Tryuk examines the views of immigration officers about the status, place and role of interpreters in relation to the norms prescribed by the Polish Code of Sworn Translators and Interpreters. The study reveals that the officers' actual expectations of asylum hearings interpreters always come into contradiction with the idealist image of interpreters as machines. Instead of merely abiding by the principles of invisibility, impartiality, neutrality and faithfulness, interpreters in Polish refugee hearings often assume a variety of roles as mediators.

In Chapter 10, 'The voice of compassion: Exploring trauma-informed interpreting', Bancroft investigates the interpreting for trauma survivors, and explores needs assessment data, development and delivery of two trauma-informed interpreting (TII) training programmes: supporting communicative autonomy; self-care for survivors and vicarious trauma reducing for interpreters. As an emerging specialized field in PSIT, TII requires a special training for interpreters to navigate the fuzzy boundaries of their roles, and meet a threefold challenge: (1) develop the skills and knowledge to interpret competently and professionally for trauma survivors; (2) reduce or prevent interpreters' vicarious trauma, as evidenced in their getting dizzy, nauseated or fearful after interpreting for survivors; and (3) balance professional ethics with humanity.

Valero-Garcés and Tipton's insightful volume makes a timely contribution to public policy development in the field of translation and interpreting studies. It seeks to investigate the influence of ethical and ideological issues on interpreters and translators against the backdrop of shifting political, social and legal landscapes. On the one hand, it analyses not only the power relations between states and limited language proficiency speakers, but also the interpreter's role in ethical dilemmas as well as the role of states and institutions in dealing with human need and rights. On the other hand, it explores the 
relations between PSIT and social inclusion, political participation, recognition, equality, and justice. Thus, this volume surpasses many of its previous counterparts, both in width and depth of the research area within the field of PSIT, and contributes enormously to its professionalization and standardization.

In terms of design, this book is accessible and friendly to readers. Nearly every article follows the same structure: introduction, background, research methodology and aims, theoretical elaboration/surveys and interviews, analysis and findings, and conclusion. In addition, tables and figures, abbreviations and theme index are also provided for readers' reference. Moreover, the ten contributors are renowned educators, researchers and practitioners specializing in PSIT with long-term experience in the field. Hopefully, their research can draw more attention from public policymakers and encourage them to include interpreting and translation on their policy agendas.

However, there are some aspects that need improvement. Firstly, the research merely deals with legal events within the European context, excluding research on PSIT in some other countries where PSIT has been booming in recent years. Secondly, although an inter-disciplinary approach and various theoretical perspectives can shed light on our understanding of conflictual situations in PSIT, its professionalization entails a more comprehensive and systematic theoretical perspective to integrate all relevant research into the framework of PSIT studies.

Overall, the volume is highly informative and illuminating. Its empirical research and insightful findings provide valuable references for scholars of translation and interpreting studies, service providers and public policymakers. Its comprehensive analysis makes it an important book for students, researchers and professional translators interested in the field.

\section{References}

Camayd-Freixas, E. (2013). Court interpreter ethics and the role of professional organizations. In C. Schäffner, K. Kredens, \& Y. Fowler (Eds.), Interpreting in a changing landscape (pp. 15-30). Amsterdam: John Benjamins.

Corsellis, A. (2008). Public service interpreting: The first steps. Basingstoke \& New York: Palgrave Macmillan.

Gentile, A., Ozolins, U., \& Vasilakakos, M. (1996). Liaison interpreting. Melbourne: Melbourne University Press.

Hale, S. (2007). Community interpreting. Basingstoke: Palgrave Macmillan.

Munyangeyo, T., Rabadán-Gómez, R., \& Webb, G. (2016). Challenges and opportunities in public service interpreting. London: Palgrave Macmillan.

\section{Liu Lisheng}

Xuchang University, China

kevinlls@163.com 